\title{
Flexibility First-A Janus-Head Ligand in Iron Coordination
}

\author{
Christian Kling, Dirk Leusser, Thomas Stey, and Dietmar Stalke* \\ Institut für Anorganische Chemie der Universität Göttingen, Tammannstrasse 4, 37077 Göttingen, Germany \\ Supporting Information
}

ABSTRACT: In this communication iron complexes of the Janus-head ligand bis(2-benzothiazolyl)phosphanide $\left((\mathrm{bth})_{2} \mathrm{P}^{-}\right.$, with bth = CNS$\left.\left(\mathrm{C}_{6} \mathrm{H}_{4}\right)\right)$ are presented. The ability to introduce a metal atom selectively to designated coordination sites is remarkable. Two different complexes underline the flexibility of this ligand toward the same metal in the same oxidation state. N,N-chelation and P-terminal coordination to the same metal in the same + II oxidation state is found in $\left[\mathrm{Fe}\left\{(\mathrm{bth})_{2} \mathrm{P}\right\}_{2}\right]$ (1) and $\left[\mathrm{Cp}(\mathrm{CO}) \mathrm{FeP}(\mathrm{bth})_{2}\right]_{2}(2)$, respectively.

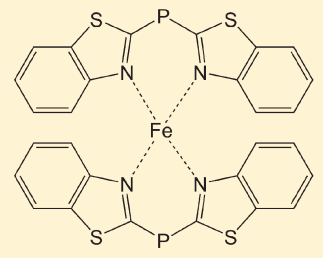

1

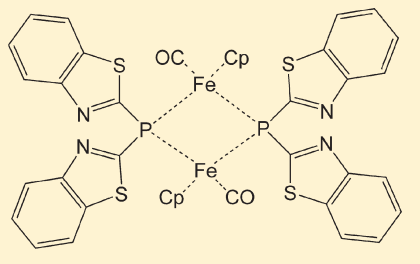

2
Tigand design is regarded as an important area in the develLopment of efficient, profitable, and sustainable catalysts in industrial processes, addressing the fact that even small changes in the ligand periphery of an active organometallic molecule can dramatically alter yields, product uniformity, selectivity, and turnover numbers. As a consequence, the synthesis and optimization of new ligands at catalytically active metals is a very important field of chemistry. ${ }^{1}$ Mainly on the basis of metal amido chemistry, ${ }^{2}$ new hemilabile main-group and transition-metal P, $\mathrm{N}$-chelating ligands have been designed. ${ }^{3}$ Our group is interested in the synthesis and characterization of metal complexes with Janus-head ligands. ${ }^{4}$ These ligands contain at least two different coordination sites with different complexation formation constants. When they are oriented in different directions, they might serve as molecular staples in bi- or heterobimetallic compounds, 5 which might turn out to be useful catalysts. The N,P,N-ligand bis(benzothiazol-2-yl)phosphane $(\mathrm{P}(\mathrm{bth})(\mathrm{Hbth})$, with bth = CNS $\left(\mathrm{C}_{6} \mathrm{H}_{4}\right)$ ) contains a divalent phosphorus atom because the hydrogen atom of this secondary phosphane is located at one of the ring nitrogen atoms, forming an intramolecular hydrogen bridge.

As part of our studies of ligand design for iron-centered metal complexes we here communicate $N, N$-bis $\{$ bis(2-benzothiazolyl)phosphanide $\}$ iron (1). The phosphanide ligand contains three different potential donor sites of various hardnesses ${ }^{6}$ and metal site selectivities. ${ }^{5 b, c}$ It turned out that the best strategy in the synthesis is to employ [iron(II)bis $\{$ di(trimethylsilyl)\}amide] to introduce the metal via a deprotonation reaction of the secondary di(2-benzothiazolyl)phosphane. The starting materials react in a ligand to amide ratio of $2: 1$. This is in contrast to all other reactions of bis(2-benzothiazolyl)phosphane with metal bis $\{$ bis(trimethylsilyl)\}amides known so far, which normally react in a $1: 1$ ratio (Scheme 1$).^{7}$

$N, N$-Bis $\{$ bis (2-benzothiazolyl)phosphanide $\}$ iron (1) crystallizes in the triclinic space group $P \overline{1}$ (Figure 1). The asymmetric unit contains two complete formula units as well as a lattice toluene molecule. Both metal complexes differ only marginally,
Scheme 1. Preparation of $[N, N-B i s\{b i s(2-$ benzothiazolyl)phosphanide $\}$ iron] (1)
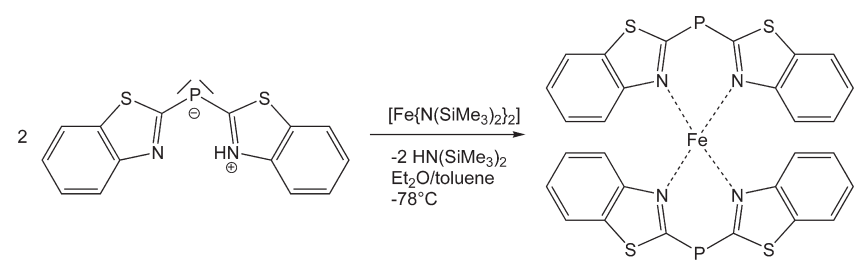

1

and consequently all given values are averaged over analogous features. Surprisingly, in $\mathbf{1}$ the iron atom is exclusively 4-fold coordinated by the nitrogen atoms of the four heteroaromatic five-membered rings. Unlike the case in life science systems, a possible $\mathrm{Fe}-\mathrm{S}$ coordination is prevented in $\mathbf{1}$. A hypothetical planar coordination of the $\mathrm{Fe}$ (II) metal atom as in natural systems and materials containing porphyrins ${ }^{8}$ is precluded as well by the steric demand of the annulated benzene rings. A square-planar coordination would not suit the $d^{6} \mathrm{Fe}$ (II) iron either. Therefore, the coordination polyhedron at the iron atom in this paramagnetic 14-valence-electron complex is best described as tetrahedral. Both ligand mean planes intersect at an almost ideal right angle $\left(82^{\circ}\right)$, and the benzothiazolyl planes of each phosphanide ligand are only twisted by 4.3 and $12.3^{\circ}$, respectively. The $\mathrm{Fe}-\mathrm{N}$ bond lengths in $\mathbf{1}$ are similar to those reported in the $\mathrm{CCDC}$ for $\mathrm{Fe}(\mathrm{II})-\mathrm{N}$ distances and range between those of an amidic and a longer dative bond. ${ }^{9}$

The $\mathrm{P}-\mathrm{C}_{\text {ipso }}$ bond lengths are on average $177.7 \mathrm{pm}$ long and range between those of a single- and a double-bond length. Due to the changes in bond lengths in the benzothiazole substituents, charge transfer from the phosphorus atom to the heteroaromatic

Received: $\quad$ March 4, 2011

Published: April 05, 2011 


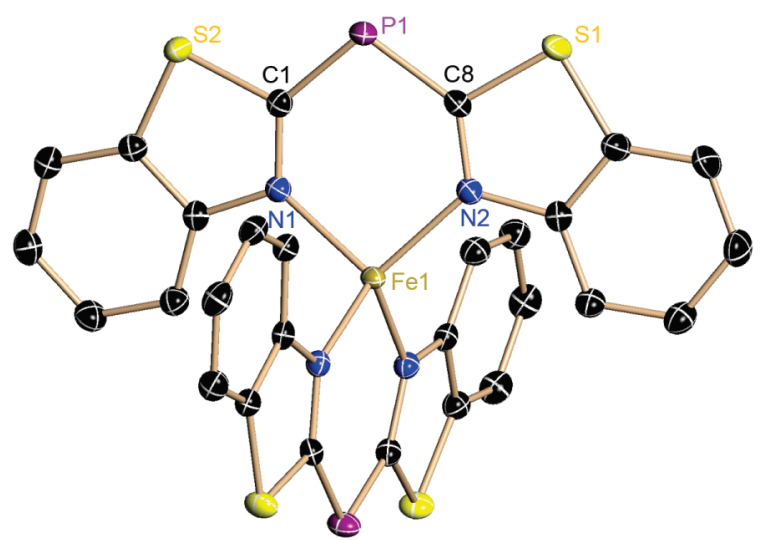

Figure 1. Solid-state structure of $N, N$-bis $\{$ bis(2-benzothiazolyl)phosphanide iron (1). The anisotropic displacement parameters are depicted at the $50 \%$ probability level, and the hydrogen atoms are omitted for clarity. Selected bond lengths (pm) and angles (deg): average $\mathrm{N}-\mathrm{Fe}$, 201.01(17); $\mathrm{P}-\mathrm{C}_{\mathrm{ipso}}, 177.7(2) ; \mathrm{S}-\mathrm{C}_{\mathrm{ipso}}, 176.2(3)$; N-C $\mathrm{C}_{\text {ipso, }}$ 133.6(3); $\mathrm{C}_{\text {ipso }}-\mathrm{P}-\mathrm{C}_{\mathrm{ipso}}, 104.0(2)$.

Scheme 2. Preparation of the (Carbonyl)(cyclopentadienyl) $\{\boldsymbol{P}$-bis (2-benzothiazolyl)phosphanide iron Dimer (2)

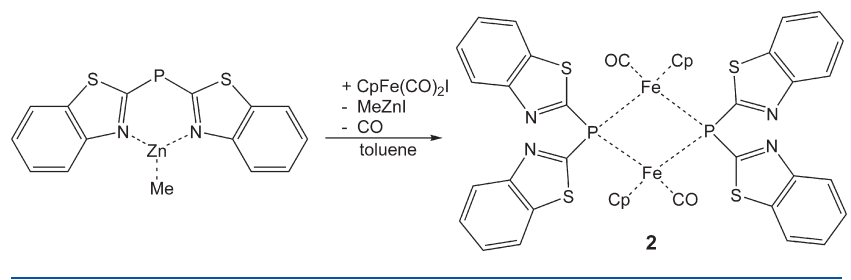

rings is anticipated but a partial $\mathrm{P}=\mathrm{C}_{\mathrm{ips}}$ bond can be ruled out. $^{6,10}$

In another experiment we tried to address the $\mathrm{P}$ and/or $\mathrm{S}$ face of the Janus-head bis(2-benzothiazolyl)phosphane ligand and employed $\left(\eta^{5}\right.$-cyclopentadienyl)dicarbonyliron iodide to replace either the $\mathrm{CO}$ or iodide function by the soft coordination site of the phosphanide ligand. Unlike the last experiment, we employed (methyl)\{bis(2-benzothiazolyl)phosphanide $\}$ zinc in a transmetalation reaction. Both starting materials were stirred in toluene for $24 \mathrm{~h}$. After filtration the solution was concentrated and stored at room temperature for crystallization. Red single crystals suitable for an X-ray diffraction experiment were obtained. The structure analysis revealed them to consist of the (carbonyl) (cyclopentadienyl) \{P-bis(2-benzothiazolyl)phosphanide \}iron dimer (2) (Scheme 2 ).

Unlike compound 1, the iron complex 2 is an 18 -valenceelectron complex. The organometallic residue is coordinated to the phosphorus atom of the ligand. In comparison to the iron in $\mathbf{1}$ the $\mathrm{CO}$ and $\mathrm{Cp}$ ligands supply a significant amount of electron density to the metal and thus change the character of the atom to a much softer center. Interestingly, $\mathbf{2}$ is not only the product of a simple direct metal exchange but can be rationalized by methyl zinc iodide elimination and the simultaneous loss of CO. $\mu$-P coordination of the ligand generates an $(\mathrm{Fe}-\mathrm{P})_{2}$ four-membered ring (Figure 2). A similar structural motif was earlier reported for the bis(2-pyridyl) phosphanides. ${ }^{11}$

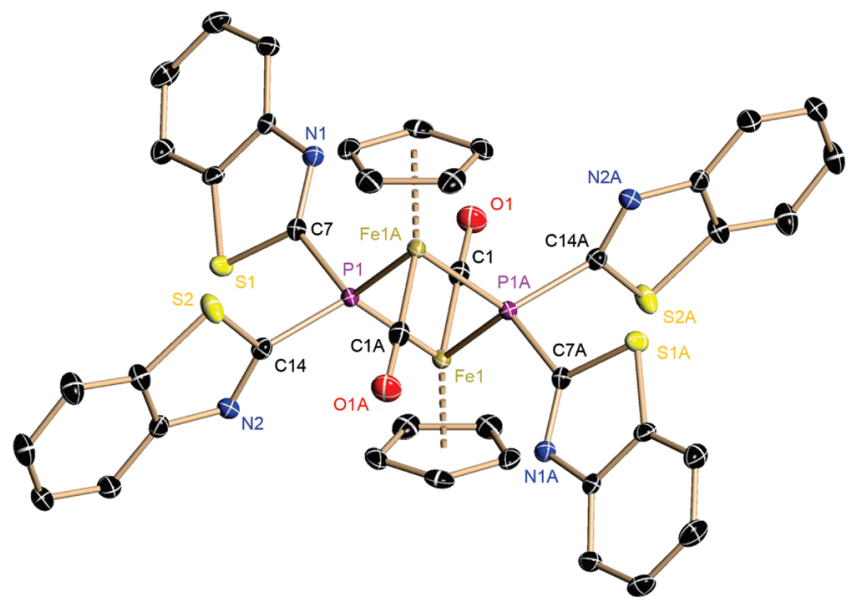

Figure 2. Solid-state structure of the (carbonyl)(cyclopentadienyl)$\{P$-bis(2-benzothiazolyl)phosphanide $\}$ iron dimer (2). The anisotropic displacement parameters are depicted at the $50 \%$ probability level, and the hydrogen atoms are omitted for clarity. Selected bond lengths ( $\mathrm{pm})$ and angles (deg): average $\mathrm{P}-\mathrm{Fe}, 223.71(6) ; \mathrm{Fe}-\mathrm{Cp}, 172.04(12) ; \mathrm{Fe}-\mathrm{Cl}$, $175.2(2) ; \mathrm{P}-\mathrm{C}_{\text {ipso }}, 184.456(20) ; \mathrm{C}_{\mathrm{ipso}}-\mathrm{P}-\mathrm{C}_{\mathrm{ipso}}, 94.2(1)$.

The (carbonyl)(cyclopentadienyl $\{$ P-bis(2-benzothiazolyl)phosphanide $\}$ iron dimer (2) crystallizes in the triclinic space group $P \overline{1}$. The asymmetric unit contains half of the dimer. The iron(II) atom is 4-fold coordinated by carbon monoxide, a cyclopentadienyl ring, and two phosphorus atoms of the bis (2-benzothiazolyl)phosphanide ligands. The average $\mathrm{Fe}-\mathrm{P}$ bond distance of $223.7 \mathrm{pm}$ is in the range of a standard $\mathrm{Fe}-\mathrm{P}$ bond length reported in the CCDC $(224.8 \mathrm{pm}){ }^{8}$ Different from the case for $\mathbf{1}$, the ligand in $\mathbf{2}$ is not planar. The $\mathrm{C}-\mathrm{P}-\mathrm{C}$ angle is $94.2^{\circ}$, and the best mean planes of the twisted benzothiazolyl moieties intersect at an angle of $93^{\circ}$. The phosphorus atoms are 13.9 and $14.7 \mathrm{pm}$, respectively, out of their best planes. The phosphorus atom is 4-fold coordinated in a tetrahedral environment. The $\mathrm{C}_{\mathrm{ipso}}-\mathrm{P}-\mathrm{C}_{\mathrm{ipso}}$ angle in 2 is only $94.2^{\circ}$, while it is widened to $104.0^{\circ}$ in $\mathbf{1}$ by the $\mathrm{N}, \mathrm{N}$-chelation. The $\mathrm{P}-\mathrm{C}_{\text {ipso }}$ bonds are elongated by $8.8 \mathrm{pm}$ to $184.5 \mathrm{pm}$ on average in comparison to 1 and therefore are in the range normally quoted as a classical $\mathrm{P}-\mathrm{C}$ single bond. All these facts point to an $\mathrm{sp}^{3}$-hybridized phosphorus atom.

In solution, the equivalency of both benzothiazole substituents in $\mathbf{2}$ is underlined even if the NMR studies are hampered due to the expected paramagnetic feature of the iron atom in $\mathbf{1}$. The observed downfield shift in the ${ }^{31} \mathrm{P}$ NMR of $\mathbf{2}$ hints at a lower charge concentration at the phosphorus atom in comparison to the uncoordinated ligand. ${ }^{12}$

In conclusion, it should be noted that this is the first and only reported complex of the bis(2-benzothiazolyl)phosphanide as a Janus-head ligand that can be addressed by the two different coordination sites. Two different coordination motifs of the same ligand with the same metal in the same oxidation state are presented. On the one hand, a dual N,N-coordinated iron complex with only 14 valence electrons is accessible by the addition of iron(II) bis\{bis(trimethylsilyl) $\}$ amide to the pure ligand. On the other hand, an 18-valence-electron complex with a strong phosphanidic character is applicable by transmetalation. This demonstrates the flexibility of the employed bis(2-benzothiazolyl)phosphane, particularly useful to catalytic applications. Thanks to the differently used coordination sites, various heterobimetallic complexes containing iron are feasible. 


\section{ASSOCIATED CONTENT}

S Supporting Information. Text giving experimental details and a table and CIF files giving crystal data for $\mathbf{1}$ and 2 . This material is available free of charge via the Internet at http://pubs. acs.org. Experimental crystallographic data, including the coordinates of both complexes, are also available from the CCDC: 802685 (1) and 802686 (2).

\section{AUTHOR INFORMATION}

\section{Corresponding Author}

*Fax: +49-551-39-3459. Tel: +49-551-39-3000. E-mail: dstalke@ chemie.uni-goettingen.de.

\section{ACKNOWLEDGMENT}

We are grateful to the Deutsche Forschungsgemeinschaft, in particular to the DFG Priority Program 1178 Experimental charge density as the key to understand chemical interactions. Support from the DNRF in the Center of Materials Crystallography (CMC) and the Catalysis for Sustainable Synthesis (CaSuS) Ph.D. program of the Land Niedersachsen is equally acknowledged.

\section{REFERENCES}

(1) Cornils, B.; Herrmann, W. A.; Muhler, M.; Wong, C.-H. Catalysis from A to Z: A Concise Encyclopedia; Wiley-VCH: Weinheim, Germany, 2007.

(2) Kempe, R. Angew. Chem. 2000, 112, 478; Angew. Chem., Int. Ed. 2000, 39, 468.

(3) Panda, T. K.; Roesky, P. W. Chem. Soc. Rev. 2009, 38, 2782.

(4) Reviews: (a) Mahalakshmi, L.; Stalke, D. The R2M+ Group 13 Organometallic Fragment Chelated by P-Centered Ligands in Structure and Bonding - Group 13 Chemistry I; Springer-Verlag: Heidelberg, Germany, 2002. (b) Baier, F.; Fei, Z.; Gornitzka, H.; Murso, A.; Neufeld, S.; Pfeiffer, M.; Rüdenauer, I.; Steiner, A.; Stey, T.; Stalke, D. J. Organomet. Chem. 2002, 661, 111.

(5) (a) Murso, A.; Stalke, D. Dalton Trans. 2004, 2563. (b) Stey, T.; Henn, J.; Stalke, D. Chem. Commun. 2007, 413. (c) Stey, T.; Pfeiffer, M.; Henn, J.; Pandey, S. K.; Stalke, D. Chem. Eur. J. 2007, 13, 3636.

(6) Henn, J.; Meindl, K.; Oechsner, A.; Schwab, G.; Koritsanszky, T.; Stalke, D. Angew. Chem. 2010, 122, 2472; Angew. Chem., Int. Ed. 2010, 49, 2422.

(7) For example: Stey, T.; Stalke, D. Z. Anorg. Allg. Chem. 2005, 651, 2931.

(8) For example: Wong, W.-K.; Zhu, X.; Wong, W.-Y. Coord. Chem. Rev. 2007, 251, 2386.

(9) Cambridge Strucutral Database, release 5.31, 2009.

(10) Kocher, N.; Leusser, D.; Murso, A.; Stalke, D. Chem. Eur. J. 2004, 10, 3622.

(11) Pfeiffer, M.; Stey, T.; Jehle, H.; Klüpfel, B.; Malisch, W.; Chandrasekhar, V.; Stalke, D. Chem. Commun. 2001, 337.

(12) Schmidbaur, H.; Buchner, W.; Scheutzow, D. Chem. Ber. 1973, $106,1251$. 